\title{
PROGNOSIS IN DISEASE OF MAJOR CEREBRAL VESSELS
}

\author{
J. L. G. Thomson, M.D., M.R.C.P., D.M.R.D. \\ Radiologist, Frenchay Hospital, Bristol
}

THE natural history of cerebrovascular disease has aroused interest recently, particularly with a view to providing a base-line against which to assess different forms of treatment. Pincock (1957) followed up ror patients with cerebral thrombosis after discharge from hospital and found that $55(54 \%)$ had died within seven years. Marshall and Shaw (I959) were able to follow up 25 I patients leaving hospital with a diagnosis of cerebrovascular disease, and they found that over half of those suffering from unilateral hemisphere lesions were dead within four to nine years. Of the 23 cases of internal carotid artery thrombosis in this group, 12 had died. Lindgren (1958) followed up 65 patients with internal carotid or middle cerebral artery occlusion and found that a third of these cases were dead within two years. Paillas (1955) found 11 deaths in 32 cases of internal carotid artery occlusion and no deaths in 12 cases of middle cerebral artery occlusion.

In Bristol in the last five years we have encountered 9I cases of partial or complete obstruction in the carotid or middle cerebral arteries, diagnosed by arteriography, and considered to be the cause of the patients' symptoms. Some of these cases were in-patients at this hospital, particularly of the neurosurgical unit, but many others were referred from other hospitals both in the city and in other parts of the south-west region. The follow-up of these 9I cases was undertaken with a view to providing further information about the natural history of this aspect of cerebrovascular disease.

\section{Material}

\section{Distribution}

The distribution of the lesions is shown in Table I. It will be noted that the majority (53) occurred at or close to the origin of the internal carotid artery in the neck, and that another considerable group ( 16 ) occurred in the siphon, a further few occurring either at or below the foramen lacerum level or in the common carotid artery. There were 15 cases in which the lesion occurred in the middle cerebral artery.
TABLE I

Site and Nature of Obstruction

\begin{tabular}{l|l|r}
\hline \multicolumn{1}{c|}{ Site } & Obstruction & No. \\
\cline { 1 - 1 } Common carotid artery & $\begin{array}{l}\text { Partial } \\
\text { Complete }\end{array}$ & I \\
I \\
\hline $\begin{array}{l}\text { Origin of internal carotid } \\
\text { artery, }\end{array}$ & $\begin{array}{l}\text { Partial } \\
\text { Complete }\end{array}$ & I9 \\
34 \\
\hline Carotid siphon & Partial & 8 \\
Complete & 8 \\
\hline $\begin{array}{l}\text { Mid-portion of internal carotid } \\
\text { artery }\end{array}$ & Partial & 3 \\
Middle cerebral artery & Complete & 2 \\
\hline & Partial & 3 \\
\hline & Complete & I2 \\
\hline & Total & 91 \\
\hline
\end{tabular}

Age and Sex

Cases ranged from 8-8I years in age with an average of 53 years. Males outnumbered females by 2 to $\mathrm{I}$.

\section{Onset}

The clinical syndrome is now well recognized, and no analysis has been made of the presenting symptoms, apart from the speed and type of onset. Thus it was apparent that about one-third of these cases had suffered a hemiparesis or hemiplegia of sudden or dramatic onset, only two-thirds of these, however, showing a complete vessel occlusion at arteriography, the rest showing a partial obstruction. About one-half of the 9I cases had a history of one month's duration or longer either of a slowly progressive type or of the so-called 'stuttering' type. A few cases had had symptoms for longer than one year.

\section{Results of Follow-up}

\section{Internal Carotid Artery Occlusion}

Nineteen cases showed partial obstruction in the internal carotid artery at or close to its origin in the neck, and, of these, nine cases were submitted to surgery. No attempt, however, was made to produce comparable groups of cases and 
so these figures should not be misread as indicating the merits of one form of treatment over another. Only a proportion of cases was considered suitable for surgery, others being rejected for various reasons such as age, general condition, hypertension and other vascular lesions, either in the brain or in the cardiovascular system elsewhere. Of the ro cases treated conservatively, two are now well (i.e. back at work or the equivalent) two to seven months after diagnosis, three are still hemiparetic I 5 months to two years later (one improving), and five died within three weeks to one year. Of the nine cases operated on, by several surgeons, four are well 15 months to three years later, two remain hemiparetic, and three died within a few days of operation.

In the 34 cases with complete occlusion at or close to the origin of the internal carotid artery, I I patients are now well five months to three years later, 14 are still hemiparetic (eight improving), and five died within a few weeks of diagnosis; one could not be traced. Of the three cases submitted to surgery, two died within the next ro months and the other one could not be traced.

\section{Siphon Occlusion}

Defining the siphon as the S-shaped loop of internal carotid artery alongside the sella turcica, there have been eight cases in which a partial obstruction has occurred. Of these, four are well six months to two years after diagnosis, another was well at two years but then died of myocardial infarction, and the other three cases are hemiparetic 8 to 12 months after diagnosis but are all improving.

Of the eight cases with a complete obstruction at this level, four are well one to five years after diagnosis, two remain hemiparetic 15 , months to five years later (one improving), and one is dead. One case could not be traced.

\section{Middle Cerebral Artery Occlusion}

Of the three cases with partial obstruction, two are hemiparetic 18 months to three years later (one improving, one worse), and one is dead. Of the 12 cases with complete obstruction, three are well one month to three years later, three are hemiparetic two months to four years later (one improving), and two died one day and two weeks later; four could not be traced.

\section{Other Sites}

These include obstructions in the common carotid artery and the mid-portion of the internal carotid artery. Of the seven cases, four are well three months to four years later, one shows no change at 14 months, one is dead, and one could not be traced.

\section{All Sites}

The follow-up on the whole group of 91 cases is shown in Table 2.

Table 2

Follow-up of 9i Cases of Arterial Obstruction

\begin{tabular}{|c|c|c|}
\hline $\begin{array}{l}\text { Time After } \\
\text { Diagnosis }\end{array}$ & No. & Condition \\
\hline I mth. -5 yrs. & 33 & $\begin{array}{l}\text { Well ( } 1 \text { died of myocardial } \frac{\bar{\rho}}{\Phi} \\
\text { infarction at } 2 \text { years). }\end{array}$ \\
\hline 2 mths. -5 yrs. & 30 & 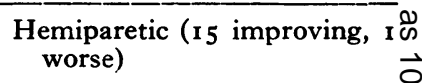 \\
\hline \multirow[t]{2}{*}{ Up to ro mths. } & 20 & Dead \\
\hline & 8 & Not traceable \\
\hline
\end{tabular}

\section{Discussion}

In contrast to the series published by Paillas. already mentioned, these figures indicate that the $\vec{N}$ prognosis of those cases with a lesion in the carotid artery has been better than those with a lesion in the middle cerebral artery. On theoretical groundso this might almost be expected, for, if the circle of ${ }_{-}$ Willis remains unaffected by clot extending from the internal carotid artery, sufficient collateral supply may be available to prevent extensive $\overrightarrow{0}$ infarction. On the other hand, the middRe cerebral arteries are virtually end-arteries and collateral supply would have to develop throughio the brain substance from branches of the anteriơr and posterior cerebral arteries.

Regardless of where the obstruction was

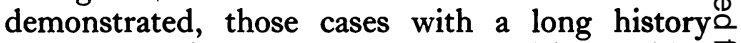
appeared to fare better than those with a sudden $\overrightarrow{\hat{O}}$ onset. In the latter group were 32 cases, and, of 3 these, Io are now well, Io are still hemiparetic, and I I are dead, the other being untraceable.

Of particular interest, as a group, are the patients with partial obstruction in the siphon, for all eight cases had a long history extending over weeks or months, all showed narrowing and irregularity of the vessel in its path alongside the sella, consistent with atheromatous plaques, and most of them did well, albeit after some initial $\frac{}{2}$ deterioration, so that over half actually returned to $?$ work and the remainder all show continued improvement. No follow-up arteriograms have been $\tilde{\sigma}$ carried out, so that the present state of the obstruc- $N$ tion, whether still partial or now complete, has not been ascertained. But, in regard to this matter, $\omega$ one case of partial obstruction at the lower end of the internal carotid artery was of interest, for two arteriograms were performed at 15 months' $\mathscr{\infty}$ interval, and these showed only a minor increase in the irregularity and narrowing of the vessel lumen. The patient had received no active treatment dur- $\overrightarrow{\mathbb{D}}$ ing this period and symptomatically showed only $\frac{\text { P }}{\mathrm{D}}$ 
minimal deterioration. It is possible, therefore, for partial obstruction to persist for a long time.

In regard to the effect of a raised blood pressure on the prognosis, there were I9 cases with a diastolic pressure of IIO $\mathrm{mm}$. $\mathrm{Hg}$ or more. Of these, four are well, six are hemiparetic still, and eight are dead, the other being untraceable. Similarly, there were 32 cases with a blood pressure of $160 / 100 \mathrm{~mm} . \mathrm{Hg}$ or more, and, of these, seven are now well, 12 are hemiparetic, and 12 are dead, the other being untraceable. Hence it appears that those with a high blood pressure fared worse than the others.

The age of the patient also appeared to have some effect, in that there were 28 cases under 50 years of age and, of these, 13 are well, ro are hemiparetic, and five are dead, indicating that this younger group fared better than the older.

Although no attempt was made to carry out a controlled trial of anticoagulant therapy, it has been noted that $\mathrm{i} 4$ of these cases were treated with anticoagulants for varying periods of time. Half of these had partial and the other half complete blocks in the artery. Of these 14 cases, five are now well, five are hemiparetic, and four are dead, which suggests that this form of treatment probably had little, if any, effect on the prognosis.

Of the total group of 9I cases therefore, it was the patient under 50 years of age, with a long initial history, a normal blood pressure and a partial obstruction in the carotid artery who had the most favourable prognosis.

\section{Summary}

In the last five years, 9r cases with partial or complete obstruction in the carotid artery or the middle cerebral artery have been diagnosed by arteriography.

These cases have been followed up and the results analysed, particularly in regard to the effect on the prognosis of the age of the patient, length of history, state of the blood pressure and the site of the lesion.

My thanks are due to the many consultants who allowed me to refer to their clinical notes, and to the numerous family doctors who replied to letters of enquiry about their patients.

\section{REFERENCES}

Lindgren, S. O. (1958): Course and Prognosis in Spontaneous Occlusions of Cerebral Arteries, Acta psychiat. scand., $33,343$.

Marshall, J., and Shaw, D. A. (r959): The Natural History af Cerebro-vascular Disease, Brit. med. F., i, r6r4.

Paillas, J. E., and Christophe, L. (1955): Les Thromboses de la Carotide Interne et de ses Branches, Rev. méd. Liège, ro, 302 .

Pincock, J. G. (1957): The Natural History of Cerebral Thrombosis, Ann. intern. Med., 46, 925. 